\title{
Casei com um homem que poderia ser meu filho: a mãe dele é mais nova do que eu
}

I Married a Man Who Could Be My Son: His Mother Is Younger Than Me

Fabio Lopes Alves

Tânia Maria Rechia Schroeder

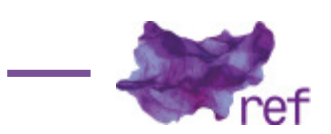

GOLDENBERG, Mirian.

Por que os homens preferem as mulheres mais velhas?

Rio de Janeiro: Record, 2017.

A narrativa, que se constitui no título dessa resenha, sintetiza um dos relatos do livro Por que os homens preferem as mulheres mais velhas, da antropóloga Mirian Goldenberg, publicado pela editora Record. Estamos diante de um trabalho que tem o potencial de aglutinar, paradoxalmente, duas características sedutoras: densidade e leveza, ao problematizar as transformações sociais contemporâneas e os novos arranjos conjugais na cultura brasileira.

A discussão do livro gira em torno de duas questões centrais: a) se, em nossa sociedade, a juventude feminina é vista como um capital, por que alguns homens invertem as escolhas amorosas e sexuais, consideradas socialmente legítimas, e se casam com mulheres mais velhas? b) se, na lógica da dominação masculina (Pierre BOURDIEU, 2010), os maridos devem ser superiores às esposas, por que algumas mulheres se casam com homens mais jovens? As perguntas acima, por si só, evidenciam a capacidade da autora de identificar e perscrutar aquilo que podemos designar como "nichos de pesquisa" nas universidades brasileiras.

Mirian Goldenberg é professora da Universidade Federal do Rio de Janeiro e, há mais de 30 anos, vem estudando os relacionamentos conjugais na contemporaneidade, sendo que, em suas pesquisas, destacam-se as seguintes temáticas: infidelidade, amor, sexo, família, envelhecimento, felicidade, liberdade. Para a escrita desse livro, a coleta de dados, somando grupos focais e entrevistas, considerou mais de cinquenta casais. É instigante a maneira como a autora busca dados do IBGE (Instituto Brasileiro de Geografia e Estatística) para mostrar que, entre 1999 e 2006, aumentaram em $36 \%$ as uniões, cujas mulheres são mais velhas que os parceiros.

Por meio dos grupos focais, a pesquisadora pôde compreender os resultados, de forma separada, no tocante ao gênero dos entrevistados. Entre os recortes metodológicos, adotados por Mirian Goldenberg, destacam-se: pesquisou casais que estão juntos há mais de dez anos; cujas mulheres são, pelo menos, dez anos mais velhas do que os maridos e, em alguns casos, mulheres 20 anos mais velhas que os maridos; todas foram casadas e possuem filhos dos relacionamentos anteriores; em alguns casos, o atual marido possui a mesma idade que os filhos ou é mais novo que os próprios filhos. Há casos em que, como diz uma das entrevistadas: "Não foi nada fácil casar com um homem que poderia ser meu filho. A mãe dele é mais nova do que eu. Foi bem difícil enfrentar o olhar de censura dela, da minha mãe e das outras mulheres" (Mirian GOLDENBERG, 2017, p. 67). 
Torna-se importante ter clareza de uma ressalva e de alguns resultados da pesquisa. Conforme a autora,

Não é minha intenção fazer neste livro uma defesa ou uma militância em prol deste tipo de arranjo conjugal. Mas é impossível não reconhecer que os casais pesquisados parecem ser muito mais satisfeitos e apaixonados do que os casais, também por mim estudados, que experimentaram outros arranjos conjugais que ocorrem mais comumente em nossa sociedade. De todos os tipos de casamentos que estudei, o que me pareceu mais feliz foi exatamente aquele em que a mulher é mais velha do que o marido. Somente nesses casamentos percebi um equilíbrio que, se não evita, ao menos minimiza os jogos de dominação, os conflitos e as disputas presentes em casamentos considerados mais "normais" ou "convencionais". (GOLDENBERG, 2017, p. 14).

O livro evidencia como a categoria corpo aparece nos discursos das mulheres casadas com homens mais jovens, bem como a maneira como as entrevistadas lidam com a decadência do próprio corpo e, consequentemente, o medo de perderem o corpo jovem, magro e atraente.

Mirian Goldenberg revela que, mesmo havendo um aumento no número de relações conjugais entre homens mais novos com mulheres mais velhas, "esse tipo de arranjo não é considerado um relacionamento 'normal' ou legítimo pela sociedade" (GOLDENBERG, 2017, p. 52). A pesquisadora foi tão perspicaz a ponto de identificar, na fala dos entrevistados, quando a esposa é mais velha do que o marido, quantos anos de diferença caracterizam uma diferença aceitável, com quantos anos de diferença passa a incomodar e quanto passa a ser significativa.

Os homens entrevistados enfatizaram que não querem uma relação associada à figura materna com suas esposas. Por isso, rejeitam quando algumas os chamam e/ou os tratam como filhos. A maneira como os casais lidam com a insegurança também foi retratada na publicação. É esclarecedor o relato da entrevistada (Bruna 57; marido 36), que diz:

Sei que meu marido sempre foi fiel, sei que ele é apaixonado por mim, sei que ele me admira. Mas, se uma noite ele chega mais tarde, ou se uma periguete fica se exibindo para ele, eu quero morrer. Preciso tomar um calmante para não explodir e estragar tudo por causa da minha insegurança. Se eu tivesse 30 anos, não teria a menor preocupação (GOLDENBERG, 2017, p. 73).

Os homens entrevistados reconhecem que seus relacionamentos são alvos de preconceitos por não se adequarem ao padrão de normalidade, sendo que, segundo diversas pesquisas de Mirian Goldenberg, ter uma esposa mais jovem é um valor, um símbolo de status e prestígio, um troféu a ser exibido (Mirian GOLDENBERG, 2007, 2008). Conforme ocorre esse desvio, alguns homens são rotulados como interesseiros, aproveitadores, malandros, mulherzinhas da relação, enquanto as mulheres podem ser acusadas de "coroa periguete", "velha ridícula", entre outros (GOLDENBERG, 2017, p. 79).

É nesse contexto que o livro conduz o/a leitor/a para a discussão sobre medo, insegurança, sofrimento, poder, preconceito, os obstáculos das sogras, tabu da idade, entre outros. A pesquisadora do Museu Nacional convoca, o tempo todo, a repensar questões que estão naturalizadas em nossa sociedade. Um exemplo disso é quando a antropóloga tira o/a leitor/a da zona de conforto, ao expor que "em vez de perguntar por que determinados homens casam com mulheres mais velhas, é preciso questionar os motivos que levam a maioria dos homens a continuar preferindo casar com as mais jovens" (GOLDENBERG, 2017, p. 125).

Recomendamos, portanto, essa publicação, não apenas aos/às antropólogos/as e sociólogos/as, mas, sobretudo, aos/às estudantes em geral (da graduação à pós-graduação), tendo em vista que a autora traz um exemplo concreto sobre como encontrar originalidade (homens que escapam à lógica da dominação masculina) dentro de um universo amplamente pesquisado.

\section{Referências}

BOURDIEU, Pierre. A dominação masculina. Trad. de Maria Helena Kühner. Rio de Janeiro: Bertrand Brasil, 2010.

GOLDENBERG, Mirian. Coroas: corpo, envelhecimento, casamento e infidelidade. Rio de Janeiro: Record, 2008.

GOLDENBERG, Mirian. O corpo como capital. São Paulo: Estação das Letras e Cores, 2007.

GOLDENBERG, Mirian. Por que os homens preferem as mulheres mais velhas? Rio de Janeiro: Record, 2017. 
Fabio Lopes Alves (iD) 0000-0002-2114-3831

Doutor em Ciências Sociais

Professor do Programa de Pós-Graduação (Mestrado e Doutorado) em Sociedade, Cultura e Fronteiras, da UNIOESTE. Membro da Comissão de Avaliação dos cursos de graduação - licenciatura e bacharelado/distância e presencial - do Conselho Estadual de Educação do Paraná e líder do Grupo de Estudos e Pesquisas em Desenvolvimento da Educação Básica (CNPq).

Universidade Estadual do Oeste do Paraná, Pedagogia

Rua Universitária, 1619 - Jardim Universitário

85819-110 - Cascavel - PR - Brasil

+55 (45) 3220-3171 - doutoradoscf@gmail.com

fabiobidu@hotmail.com

Tânia Maria Rechia Schroeder (iD) 0000-0002-3646-3088

Doutora em Educação pela Unicamp

Realizou estágios de pós-doutorado na Universidade de Paris V (Sorbonne) e na Universidade Federal de São Paulo (UNIFESP) pelo PNPD/CAPES. É professora associada da UNIOESTE. Em pesquisas atua principalmente nos seguintes temas: juventude; violência; imaginário e formação de professores. Universidade Estadual do Oeste do Paraná, Pedagogia

Rua Universitária, 1619 - Jardim Universitário

85819-110 - Cascavel - PR - Brasil

+55 (45) 3220-3171 - ppgeunioestecascavel@gmail.com

tania.rechia@hotmail.com

COMO CITAR ESSE ARTIGO DE ACORDO COM AS NORMAS DA REVISTA

ALVES, Fabio Lopes; SCHROEDER, Tânia Mara Rechia. "Casei com um homem que poderia ser meu filho: a mãe dele é mais nova do que eu". Revista Estudos Feministas, Florianópolis, v. 27, n. 1, e57057, 2019.

\section{CONTRIBUIÇÃO DE AUTORIA}

Fábio Lopes Alves - Elaboração da redação do manuscrito.

Tania Maria Rechia Schroeder - Revisão, normatização e ajustes finais do trabalho.

\section{FINANCIAMENTO}

Não se aplica

CONSENTIMENTO DE USO DE IMAGEM

Não se aplica

APROVAÇÃO DE COMITÊ DE ÉTICA EM PESQUISA

Não se aplica

\section{CONFLITO DE INTERESSES}

Não se aplica

LICENÇA DE USO

Este artigo está licenciado sob a Licença Creative Commons CC-BY. Com essa licença você pode compartilhar, adaptar, criar para qualquer fim, desde que atribua a autoria da obra.

\section{HISTÓRICO}

Recebido em 14/05/2018

Aceito em 30/06/2018 